\section{ASTONISHING DENTITIONS}

Sir, I wish to applaud your innovative 'Wildlife Series' cover illustrations in Volume 213 of the British Dental Journal. Since the dropping of comparative odontology from the dental curriculum in most, if not all dental schools, dentists are woefully ignorant of the astonishing variety of dentitions that exist in the animal kingdom. The adaptation of teeth to various diets makes a fascinating study of the diversity of dentitions that range from the shark's polyphyodont (multiple sets) to the mammalian diphyodont (two sets) of teeth. The evolution of simple cone homodont (single cusp) to heterodont (multiple cusp) teeth determines the development of the complex human dentition, and ought to underlie dentists' knowledge of the organs upon which their profession is based. I trust that you will feature such widely diverse dentitions as those of dinosaurs, reptiles, fish, rodents, tusks of walruses, narwhals and elephants to illustrate how diverse the organs of predation, capture, ingestion, mastication, speech, aggression, comeliness and even sensory input are manifest in the huge range of odontological oddities.

I enclose a photo showing the outline of a narwhal male spiral tusk (Fig. 1).

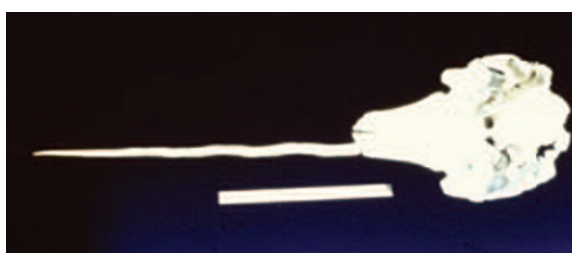

Fig. 1 Left side canine spiral tusk protruding from a male narwhal (Monodon monocerus) skull. The female lacks a tusk, representing the most extreme dental sexual dimorphism. Scale rule is $45 \mathrm{~cm}$ long. Photo courtesy of the University of Alberta Dental Museum

\section{G. H. Sperber, Canada}

Reading

1. Sperber G H. The place of physical anthropology and comparative odontology in dental education. J Dent Educ 1970; 34: 413-417.

2. Nweeia M T, Eichmiller F C, Hauschka PV et al. Vestigial tooth anatomy and tusk nomenclature for monodon monocerus. Anat Rec (Hoboken) 2012; 295: 1006-1016.

DOI: 10.1038/sj.bdj.2012.784

\section{A SUITABLE METHOD}

Sir, with reference to the article Amelogenesis imperfecta: the orthodontic perspective (BDJ 2012; 212: 485-489), the use of sodium hypochlorite to remove excess protein surrounding the enamel crystals and improve the quality of etch in amelogenesis imperfecta cases has been described. However, this study was conducted in primary teeth and the evidence for improved bracket retention with these methods remains weak, as does increasing etch times in this group of patients.

A case of amelogenesis imperfecta $(19 / \mathrm{F})$ is being treated in our department with a fixed orthodontic appliance. We have followed the recommendations of D. R. Venezie et al. ${ }^{1}$ for preparing enamel for bonding brackets. The bracket was bonded on permanent teeth. Enamel was pre-treated with 5\% sodium hypochlorite for one minute, rinsed and air dried. The bracket was bonded using Transbond $^{\mathrm{TM}}$, Unitek/3M composite. The patient has been undergoing the therapy for the last six months and we have not witnessed any bond failure so far. We are even able to disimpact a blocked out upper incisor into position (Figs 1 and 2) Thus it provides evidence that the above procedure can be considered a suitable method for achieving clinically successful bond strength.

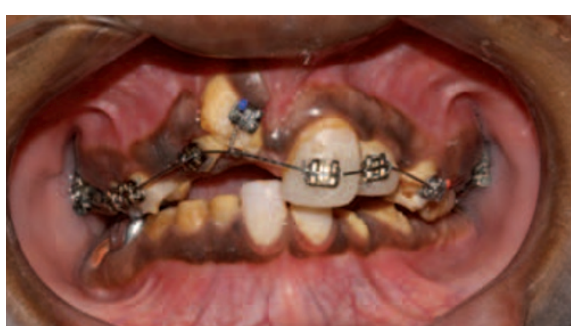

Fig. 1 Intra-oral photograph showing bonded brackets and NiTi wire in position

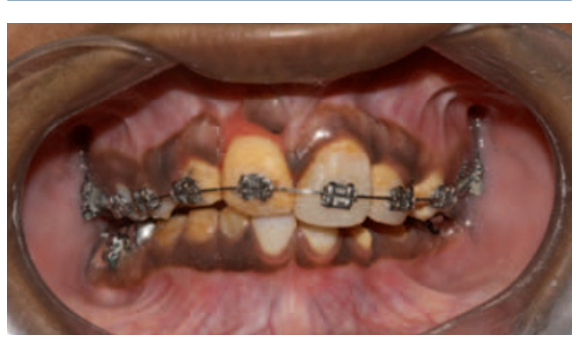

Fig. 2 Intra-oral photograph showing aligned incisors

Prasanna T. R., Sachin G. Tumkur, India

1. Venezie D R, Vadikas G, Christensen J R, Timothy Wright J. Enamel pretreatment with sodium hypochlorite to enhance bonding in hypocalcified amelogenesis imperfecta: case report and SEM analysis. Pediatr Dent 1994; 16: 433-436.

DOI: 10.1038/sj.bdj.2012.785

\section{PERITENDINITIS CREPITANS}

Sir, a healthy 45-year-old, right handed male dentist, working in a dental access centre, presented with acute incapacitating pain over the extensor aspect of the right forearm associated with a sausage-shaped swelling. He had had no previous musculoskeletal problems and was not a sportsman. Movement of the thumb was associated with audible and palpable crepitus in the forearm. The condition was treated with steroid injection and rest; it gradually settled to enable the dentist to return to work.

Peritendinitis crepitans, also known as intersection syndrome, is an unusual condition of the forearm. Thought to be inflammatory, it presents with acute pain, crepitation and a sausageshaped swelling on the lower part of the extensor aspect of the forearm 4-10 cm proximal to Lister's tubercle. ${ }^{1}$ It has a low incidence and generally settles with conservative treatment, sometimes requiring ultrasound guided steroid injection. Peritendinitis crepitans tends to occur following an increase or change in upper limb activity or after a period of rest. ${ }^{1,2}$

Dental access centres undertake a large number of surgical procedures, in particular extractions and endodontics, both of which require either gripping or rolling movements with the thumb against the fingers. With limited preventive work in between such surgical procedures, the level of activity of the hand and in particular the thumb during the working day becomes significant.

Upper limb disorders are usually of unknown aetiology but are sometimes thought to be activity related and this is particularly the case with regards to this condition. Nevertheless, given the nature of the role, a dentist would not necessarily be expected to develop a condition that would normally be associated with heavy manual or assembly line work. There are no previous case reports in the literature in the dental profession. Were peritendinitis crepitans a purely work related condition one would have expected cases to have occurred in dentists in clinical practice when extractions were common and 